\title{
Investigation and Adjustments Approaches Study on DQP Learning Areas Credits Reasonable Distribution The Case Study of Human Resource Management
}

\author{
Weimin Zhong ${ }^{1,}$ a Wei Xiong ${ }^{2, b}$ \\ ${ }^{1}$ Lingnan Institute of Technology, Guangzhou, Guangdong, China, 510663 \\ ${ }^{a}$ email, ${ }^{b}$ email
}

Keywords: DPQ, Qualifications, Frame Credits

\begin{abstract}
This paper stand in the perspective of the construction professional, systematic combing Curriculum standards, combined with DQP Qualifications Framework credits proportion under study and the distribution of the field demonstration, using methods from the top down and from the bottom relative binding framework for qualifications learning areas initial construction, the formation of professional curriculum system of traditional distribution "spider diagram." DQP Credit is an intuitive framework to quantify the construction, it can make people see clearly the focus Curriculum System, each area relative to other areas of teaching and learning time and effort to quantify the proportion of the investment, this structure allows us to able to measure, assess, and thus improved. Article explores how to build the field of learning outcomes and learning curriculum system, curriculum and learning outcomes occupational competencies between channels ways and means to achieve assess and improve DQP framework system.
\end{abstract}

\section{Introduction}

By the Guangdong Provincial Department of Education approved, Guangdong Lingnan Vocational and Technical College "Credit-based vocational education reform US DQP system" project (hereinafter referred to as "the project") in Guangdong Province in 2014 to deepen the comprehensive reform pilot project in the field of education. Qualifications Framework (DQP) is a tool for reform of higher education in the United States new development, constructed for the three degree (associate, bachelor, master) has five basic common fields of study, based on learning outcomes Qualifications Framework and US colleges and universities to get more widely used practice. DQP framework and credit combined to build describe and quantify the combined qualifications framework, the macro level, both on the same professional different academic levels in different learning areas to achieve the requirements and credit criteria to quantify for comparison studies, also features and credits can be of different professional learning outcomes in different fields of study the distribution requirements than for research, can also be a comparative study of different schools specializing in the distribution of the characteristics of learning outcomes; the micro level, in the framework of the system parameter measurement and analysis based on the realization of the construction of professional characteristics, course system, update teaching methods to enhance the interaction and promoting professional competence requirements. The main purpose of this study is to explore how to construct the framework of credits under DQP system, measuring system parameters, system assessment and means to optimize the system.

\section{The Determining Method of the Credits Distribution of Study Fields}

In the research process, using from the top down and from the bottom of the frame relative to the method of combining system was initially built. Based on previous lessons in the school curriculum sessions, successive quantization control defined credits, then the reference given course credit, and finally gives the results of the course credits. On this basis, the credit profile "spider diagram" is merely a conventional curriculum system conversion at DQP framework described it, or to use credit DPQ approach a succession of the traditional curriculum. However, DQP credit system is an 
intuitive framework to quantify the construction and it can make people see clearly the focus Curriculum System, each area relative to other areas of investment of time and energy to teaching and learning of quantitative proportion, so that we are able to measure such a configuration, evaluation, thereby improving.

Construction of frame-based credit system DQP steps from the top down as follows:

The first step: give the total credit of 120 points.

Step Two: Preliminary divided by basic courses and specialized courses conducted total credits, such as the basic course 45 hours courses 75 points.

The third step: the basis of all imputation Course lessons and courses curriculum lessons, according to preliminary consideration of the weight class to assign all credits.

Step four: the total credit constraints (weights can increase the proportion of design considerations Learning Areas), focusing on the area of study course consider learning outcomes required support, as well as credit decimal offs, mergers, rounding processing unit of stars credit courses.

Step five: of course learning outcomes to identify and describe the outcome of the formation course that is SOC (Subject Outcome). For each SOC, give credits based on the outcome of the difficulty of obtaining the required hours.

Step Six: The course outcome merged into DQP learning areas, Guangdong Lingnan Vocational and Technical College called POC, namely learning outcomes of professional norms or professional program (Program Outcome).

Step Seven: Statistical results of credits each DQP learning areas.

Step eight: the learning outcomes credits in each area to scale on a "spider diagram" to form a quantitative distribution diagram credits professional fields of study.

Construction of frame-based credit system DQP steps from the bottom as follows:

The first step: Studies in each course, identify their learning outcomes, and give preliminary credits.

Step Two: Identify each area of study course achievement belongs.

The third step: statistical summary of the results of each course credit DQP area of study belongs.

Step Four: Press the total credits (ie 120 points) constraints (can be increased to consider fields of study the weight ratio of the design), key consideration course of study in the field of learning outcomes required support, as well as credit decimal trade-offs, mergers, according to the unitization after rounding the course that deal with the outcome of the credits.

Step five: The learning outcomes of the course aggregates, obtained course credit.

Step Six: statistical summary fields of study credits (or credits in accordance with the field of credit distribution derived directly credits design fields of study).

Step Seven: Statistical results of credits each DQP learning areas.

Step eight: the learning outcomes credits in each area to scale on a "spider diagram" to form a quantitative distribution diagram credits professional fields of study.

From that we can see, under the credit system DQP framework, may be a conventional curriculum system is simple and intuitive to break down quantitative description of fields of study, or a subjective learning outcomes proposed credit distribution requirements for each area of study, and then curriculum and course learning outcomes included in the system. If you want to make a subjective right of each field of study redistribution method may be employed or expert meetings Delphi method.

\section{The Expression of Learning Outcomes}

Here we focus on the presentation of the results of the "size" requirement. Related Reference Guide to Practice, University of London, Queen Mary College of the Royal Professor Matthew Williamson written by [], the expression of learning outcomes following criteria:

$\square$ The outcomes for supplementary teaching syllabus content and not a substitute, but the results of the core curriculum output, not all outputs 
The number of outcomes is more appropriate 4-6

The statements easy to understand

$\square$ When used to express the results of the final outcome of the course to be included in the process. Such as the preparation of research papers, but also lists the process as planned, the process of collecting information, analytical processes.

$\square$ The outcome should reflect the level of hierarchy (Broome based on hierarchical representation of verbs, such as a vocabulary knowledge, comprehension, application, analysis, synthesis, evaluation, etc.), the authors believe that the learning outcomes gradation level corresponding to the level of ability can target jobs, education levels of ability levels.

$\square$ The different types of outcomes should be balanced.

Distribution of credits for each area of study, must and learning outcomes in this area linked to the performance of this outcome inevitable course of learning outcomes, namely SOC (Subject Outcome). Therefore, when the professional specification results of these fields of study, curriculum content should be the outcome of what is being said it is consistent. Some scholars believe that the learning outcomes described in the professional norms should be more macro, described the outcome of the curriculum can be more detailed, so that the learning outcomes of a professional standard, learning outcomes can contain one or more courses. Some academics have suggested the use of the results of curriculum support professional norms outcome statement. This study suggests that this approach makes learning outcome areas between (POC) and the Course outcomes (SOC) in fact is not clearly correspond. Consequences not clearly correspond to the formation of a POC outcome corresponding to a plurality of SOC results, or the results of a SOC supports a plurality of POC results, the relationship between the formations of intractable stalemate.

If POC learning outcomes and learning outcomes SOC for unified description that each of the results POC predetermined able to design and implement complete, its expression should be smaller than a course category. But the area of study results, usually presents the entire professional learning outcomes, we must have sex before, macro. This requires that each course SOC also must have a certain generality. As can be specified for learning outcome is roughly not less than the number of credits, such as not less than 0.5 credits. Even so, 120 credits can have 240 major learning outcomes can be identified is a very meticulous professional management of teaching achievements.

This study suggests that the outcome of the divided type and classification is necessary. Such as the theory and practice of learning outcomes by attribute points, based on knowledge and practical skills based on two types of outcomes; whether by direct and professional work related tasks can be divided into task-oriented and individual (citizen) quality-oriented types of learning results; results-based presentation of the classification can be divided into: oral, written report, field operations, presentations, and other types of work.

\section{The Way to Adjust the Credits Distribution}

Teaching achievement is the establishment of a unified caliber professional development, curriculum development, curriculum assessment, the introduction of a variety of work on the basis of business evaluation of the results of joint communication. This study is in this line of thinking, professional recognition of learning outcomes, based on these results-based questionnaires, so that social enterprises to evaluate the results in their work the importance, usefulness, open up professional development, curriculum development and social employment market evaluation channel between. Construction of learning outcomes whether professional guidance course construction? Course Construction Achievements can be recognized by society? Proved all these problems have a way to form a chain of information feedback, and build a closed-loop management system, to achieve continuous improvement. When the reaction of society to certain learning outcomes obviously does not endorse, adjust the teaching schedule these outcomes is necessary to optimize the entire DQP framework, namely tuning (Tuning) []. The following is the Guangdong Lingnan Vocational and Technical College of Human Resources Management to learning outcomes comb, design questionnaires were analyzed, and an example of system tuning. 
The project team conducted a manpower professional courses "curriculum outcomes form" learning outcomes comb formation. On this basis, the design of the "human resource capacity needs vocational students' questionnaire." Through the questionnaire survey and data analysis, the project team access to a wealth of professional ability of the students requested information, as shown in Figures 1 and 2.

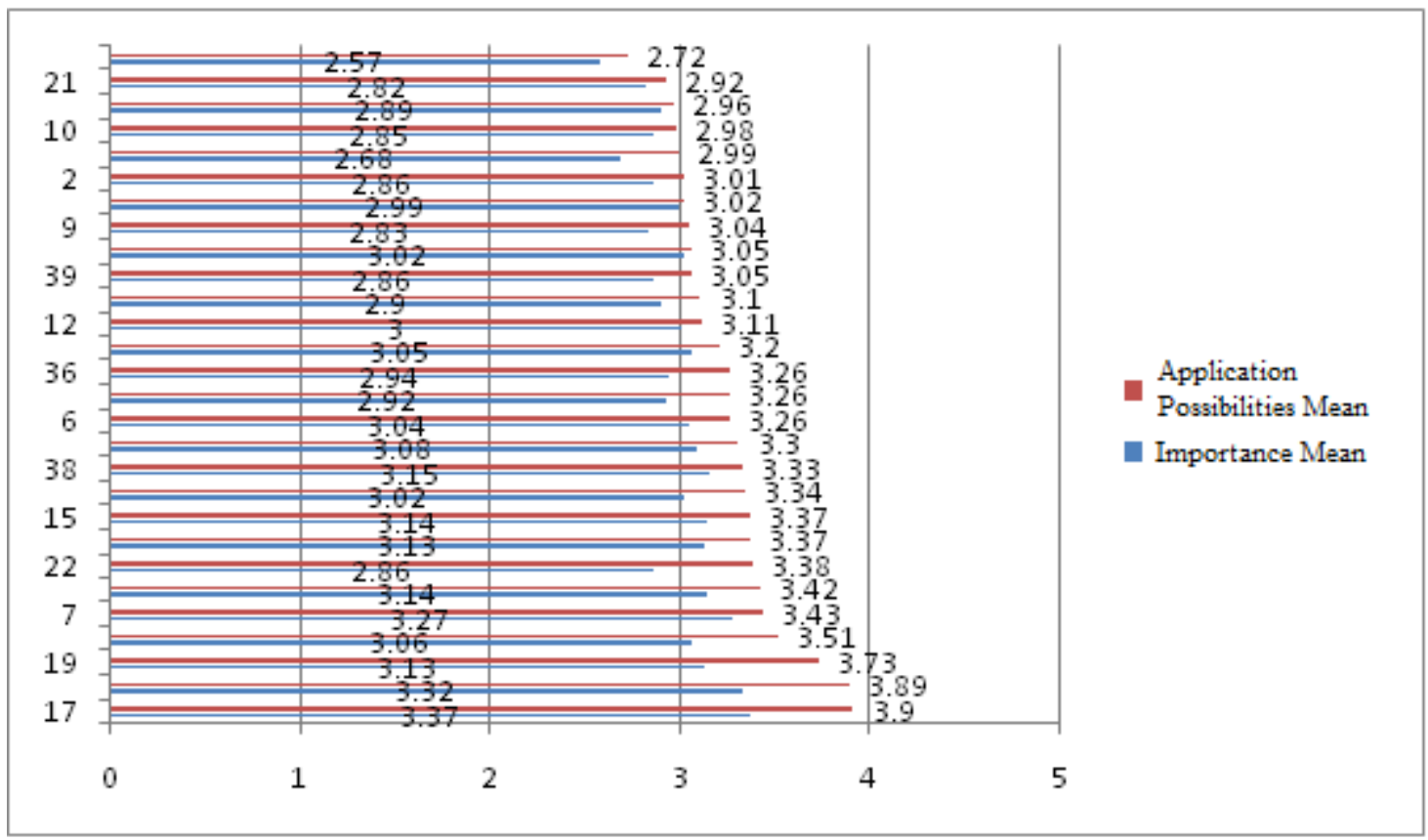

Fig 1: The importance of professional skills of each application and the possibility of the mean chart

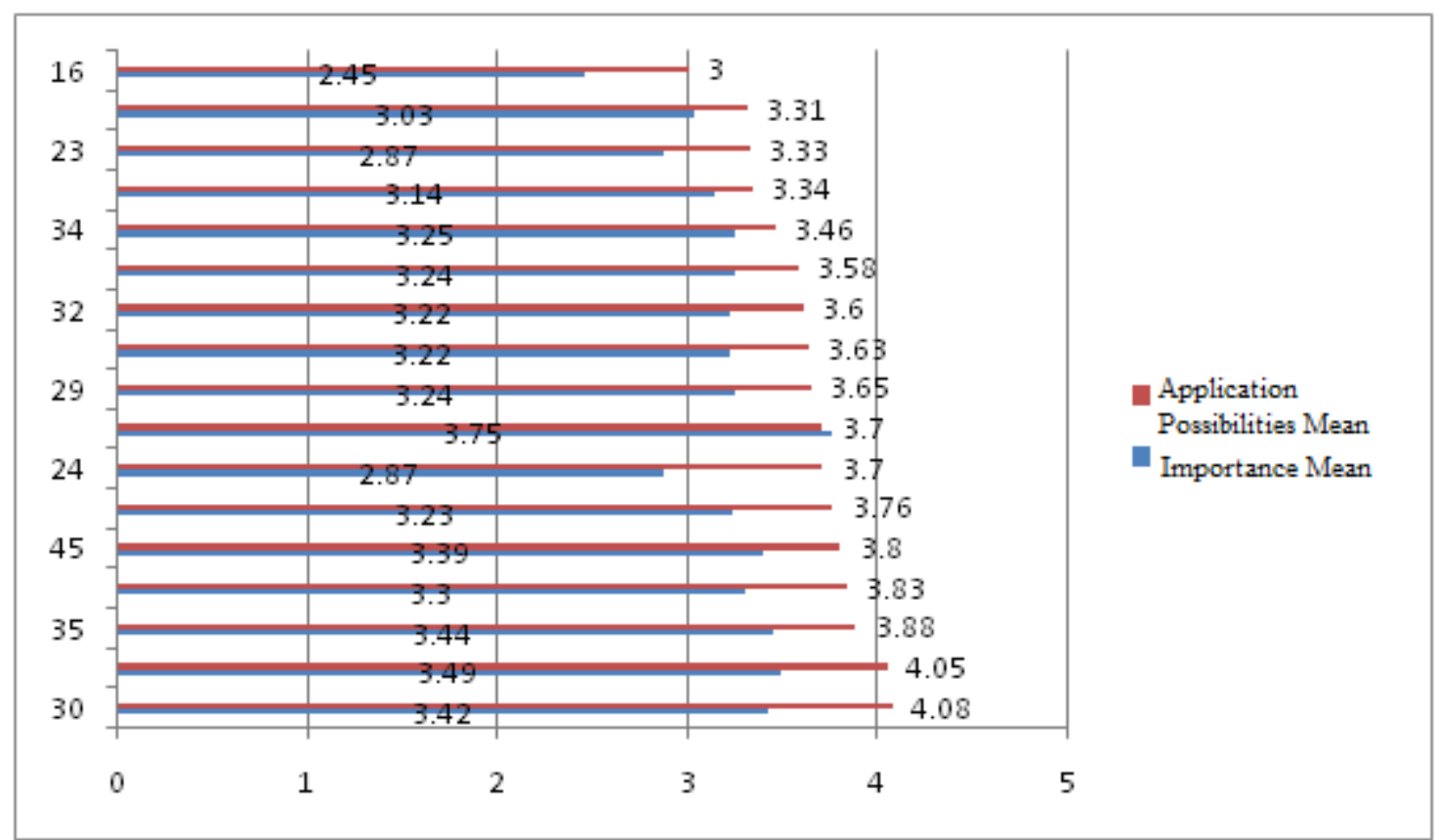

Fig 2: The importance of generic skills and application possibilities mean chart

According to research results of the project team the importance of the outcome of the course of the employer's point of view, to re-examine the results of the credit value of courses share, identify potential irregularities: some courses, such as the results of the employer point of view there is a relatively high value of the position in distribution of credit but has been neglected; and some learning outcomes does not have the status of an important value, it may be over-spending study time in the study. Final qualitative and quantitative analysis of a combination of, the guiding framework for credit system tuning. Through this investigation, we obtained course tuning recommendations are as follows: 
"Excel-based HRM" This course, if necessary, consider increasing the hours for the protection of the students hands-on time, and enhance students' ability to use the Excel software.

The curriculum, the "job analysis" content integration in "human resources planning" course. Configuration relative reduction credits.

"Business Etiquette and Communication" course to arrange a large number of training hours to effectively train students' communication skills and basic interview etiquette literacy. For basic negotiating capacity enterprises to pay attention, it is recommended also as a teaching focus. The relative increase in credit configuration.

\section{The Inadequate Aspects and Aspects Still Need to Explore}

In this study, theoretical analysis and system construction on principle strive though scientifically, but due to various reasons, such research has been limited, in this study the problem of inadequate and needs further study as follows:

(1) This study is a professional construction Higher Credit System in the United States DQP practices based DQP system needs to be in the school-wide implementation as a condition. Further study of the system and the national macro-abutting relationship education system will be implemented to promote school advantageous measures.

(2) Due to the current teaching system docking and traditional courses, temporarily unable to sort out the real implementation of the outcome of the whole professional all courses, identification, classification. Such as the current credit system in our school division of liberal arts courses, basic courses and specialized courses three categories. The division reflects the traditional institutional requirements, and the professional will not be able to build a unified framework in accordance with DQP fields of study, specific solutions needs further study.

(3) Business of professional competence of understanding, the understanding of the teaching achievements should establish a communication mechanism teaching and employers at a higher level, the specific approach needs further study.

\section{Acknowledgements}

Fund Project: Guangdong Province 2014 deepen the comprehensive reform pilot project in the field of education "Higher education credit pilot reform based on the United States DQP system"

\section{References}

[1] Yin Ming, Li Danqing, Zheng Jichang. Chinese Vocational and Technical Education, Vol. 6 (2016) No 53, p.79-80

[2] Matthew Williamson. Good Practice Guide on Writing Aims and Learning Outcomes. Queen Mary University of London [EB/OL]. http://www.ica-sae.org/trainer/english/p4.htm.

[3] Natasha A. Jankowski,David W. Marshall.Degree Qualifications Profile (DQP) and Tuning: What Are They and Why Do They Matter?[J].New Directionsfor Institutional Research, 2015 (10): 165-166.

\section{广东省 广州市 天河区 石牌街道龙口中路 173 号华天国际西苑 9D2 510630 熊}

\section{微 18819808671}

